\title{
Terrorism Transformed: The "New Terrorism," Impact Scalability, and the Dynamic of Reciprocal Threat Perception
}

\author{
By Doron Zimmermann ${ }^{*}$
}

\begin{abstract}
"The need to concentrate the greatest possible force and deliver a smashing blow at the decisive point will continue to clash with the need to outwit, mislead, deceive, and surprise the enemy. Victory, as always, will go to the side that best understands how to balance these two contradictory requirements, not just in the abstract but at a specific time, at a specific place, and against a specific enemy."1
\end{abstract}

\section{Reappraising a "New" Kind of Terrorism}

How new is the "New Terrorism," and does this paradigm accurately portray the effective threat of contemporaneous terrorism and the next wave of the near future? Moreover, do we need to fundamentally revise our conception of the terrorism paradigm in the light of a considerable number of analyses of contemporary terrorism that argue that "different motives, different actors, different sponsors, $\ldots$ and demonstrably greater lethality" exemplify this supposed new breed of political violence?2 It is probably unwise to accept the "New Terrorism," as delineated by scholars who have announced its arrival, at face value. ${ }^{3}$ Upon closer inspection, the so-called "New Terrorism" is not as deserving of the designation "new" as may appear to be the case on first sight. Thus, I suggest that a skeptical treatment of the "New Terrorist" paradigm is required, for a number of reasons. The most important argument militating against the received conception of the "New Terrorism" is the simple fact that it is potentially distorted, in that it almost invariably conveys an ill-defined, impressionistic image of

\footnotetext{
* Doron Zimmermann is Senior Researcher, Center for Security Studies, ETH Zurich, Switzerland.

${ }^{1}$ Martin Van Creveld, The Transformation of War (New York: The Free Press, 1991), 226.

${ }^{2}$ Ian O. Lesser, "Changing Terrorism in a Changing World," in Countering the New Terrorism, Ian O. Lesser, et al. (Santa Monica: RAND Corporation, 1999), 1-5; quoted passage at 1.

${ }^{3}$ For selected works propounding the appearance of the "New Terrorism," see: Harvey Kushner, "The New Terrorism," in The Future of Terrorism: Violence in the New Millennium, ed. Harvey Kushner (Thousand Oaks, CA: Sage Publications, 1998); Mark Juergensmeyer, "Understanding the New Terrorism," Current History (April 2000): 158-163; Walter Laqueur, The New Terrorism. Fanaticism and the Arms of Mass Destruction (London: Oxford University Press/Phoenix Press, 2001), especially 3-5; Bruce Hoffman, Inside Terrorism, (New York: Columbia University Press, 1998); Lesser, et al., Countering the New Terrorism.
} 
post-Cold War political violence movements (PVMs). ${ }^{4}$

By way of introduction, it must be clearly understood that the mere existence of weapons of mass destruction (WMD) - even the knowledge of how to construct, and the possibility of acquiring weapon-grade materials illegally in order to build, crude atomic, biological, and chemical devices - is not a new phenomenon, and by itself certainly does not justify the appellation of the "New Terrorism." The awareness among government analysts of the potential danger posed by WMD in the hands of non-state actors may be as recent as the end of the Cold War, but calling the problem novel for this reason is to confuse its appearance on the governmental radar with its actual inception, or to assume that "terrorists" are as a rule slow-witted dullards and uncreative, chronic underachievers.

If modern history is not characterized by effective containment of destructive technologies, neither is it marked by an absence of religious fanaticism. In the light of the historical track record of religious militancy, its recent recrudescence as embodied in Islamism therefore fails to surprise those sensitive to the currents of the past. Finally, on the score of advanced organizational principles among the "New Terrorists," it remains to be said that the terrorist groups of the 1970s were exemplars of highly sophisticated organizational structures and, if anything, have proven to be resourceful, inventive, resilient, and remarkably flexible in the face of the combined repressive force applied by the governments they opposed.

To review additional characteristics put forward by its proponents in the media and academia, the recent and widespread description of this new breed of PVM is suggestive of terrorist groups operating free from previously valid motivational constraints, with an unprecedented potential for access to WMD and/or advanced military-grade hardware, all of which are - ostensibly to be suddenly unleashed upon a defenseless public in the pursuit of some obscure, irrational, and utterly arcane agenda. The problem with this image of the "New Terrorism" is that it conveys an undifferentiated and incomplete perspective of the matter at hand. To date, one of the more convincing (and partial-

\footnotetext{
${ }^{4}$ The terminology used in this essay, specifically the term "political violence movement" (PVM), is an effort at creating a functional, and hopefully clearer, nomenclature by removing value laden, pejorative, and stigmatizing connotations inherent in the popular use of the ill-defined and instrumental term "terrorism." The term "political violence movement" subsumes religiously or politically ideologized and/or radicalized sub-state actors employing terrorist tactics in pursuit of their strategic (i.e. single-issue, political and/or religious) objectives. On this point, see Walter Laqueur, The Age of Terrorism, 149. Furthermore, David Tucker has observed: "To the extent that terrorists with religious motivations also have political and social agendas-for example the establishment of an Islamic state-they will labor under the same kinds of constraints that terrorists with political and social agendas labor under as they struggle to achieve their political goals." David Tucker, "What is New About the New Terrorism and How Dangerous is It?" Terrorism and Political Violence 13:3 (Autumn 2001): 7.
} 
ly implied) explanations for the appearance and mushrooming of the "New Terrorist" paradigm is the following by Martha Crenshaw:

Both the study of terrorism and counterterrorism policy have been eventdriven. Why has the notion of a "new," dangerous, and uncontrollable terrorism become so compelling? Is the perception driven by the shock of a series of events closely related in time but not necessarily caused by the same factors? Is the perception of threat driven by public opinion, the news media, or elites in the government and scientific community? ${ }^{5}$

If Crenshaw's assumptions regarding the driving factors behind the "New Terrorist" paradigm are valid, which appears plausible, then the fact that research on terrorism is event-driven could conceivably give rise to a more disquieting question - namely, whether the definitional debate on terrorism is the only one suffering from likely instrumentalization by vested interests among the powers that be. Should the response be in the negative, this would also seriously call into doubt the academic quality of the paradigm, and raise the issue of whose interests it serves. More generally, to what extent can the perception of a threat be generated, induced, and manipulated? Even if terrorism by insurgents of all stamps is only partially based on the precepts of psychological warfare, it follows that the means to combat it are probably not dissimilar. Unfortunately, it lies in the nature of such questions that they are not only instrumental, but also highly political and even firmly securitized.

A dimension of terrorism research that is also slighted due to the sensationalist value of terrorist attacks - as well as the mass-mediated perception of the threat represented by PVMs and governments' manic preoccupation with defensive measures at the expense of preventive endeavors - is the terrorist actor himself, his organization, his motives, and the cosmology and physical environment that spawn them. Once actor-centered and actor-related issues replace the more visually arresting blood and gore of terrorist attacks, there is very little that is authentically new in the agenda and the motivational, organizational, and even elements of the methodical aspects of the "New Terrorism."

First, the supposed novelty of the "New Terrorist" political, religious, or social program is largely dependent on the time frame involved in an analysis of terrorism, "terrorists," and terrorist acts. For what, except time and place, distinguishes the objectives (or methods) of the Sicarii of the Jewish Zealot movement from the ends pursued (and means used) more recently by supporters of the relatively obscure MAK (Maktab al-Khidamat, the Mujahedeen "Office of Services"), which subsequently gained notoriety in the guise of AlQaeda? In principle, and to some extent even in practice, there are similarities, for both movements stated their aim to cleanse hallowed soil of foreign desecrators by forcefully ejecting all unbelievers.

${ }^{5}$ Martha Crenshaw, "The Psychology of Terrorism: An Agenda for the $21^{\text {st }}$ Century," Political Psychology 21:2 (June 2000): 415. 
In the first example, the Romans under the emperors Nero and Vespasian occupied parts of Biblical Israel, thereby provoking the second of three Jewish revolts from c. 66-73 A.D. The militant Zealot movement, whose corps of knife-wielding Sicarii publicly slaughtered legionaries and their officers in bloodcurdling and spectacular fashion, ambushed Roman patrols in the countryside, poisoned wells with rotting animal corpses and, more generally, fiercely resisted the vastly superior Roman war machine as irregular combatants using unconventional, "asymmetric" tactics. The second example concerns the Western coalition troops after the Gulf War (1990-91), who had made their presence felt in the Saudi peninsula - "the land of the two Holy Places" (Medina and Mecca) - and in due course became subject to attack by radical Islamist forces, for instance at Khobar Towers in 1998.

Neither case is illustrative of a PVM motive that is in any manner diffuse or new. Nor, for that matter, does Osama bin Laden's religio-irredentist objective of resurrecting the splendor of the Caliphate of the seventh and eighth centuries (including the reestablishment of its geographic boundaries) in place of the present regimes in the Arab world exactly serve as an illustrative example of a revolutionary enterprise. Judged by any standard, Bin Laden's vision of the future is reactionary to an extent that is rare indeed.

By extension, it could be argued that Islamism merely seeks to succeed at an undertaking in the present (i.e., uniting Islam) in pursuit of conservative ideals at which Pan-Arabism has demonstrably failed in the past in pursuit of revolutionary ideals (i.e., uniting the Arab world and freeing it from Western dominance). The point is that the ideologies employed to mobilize social forces in each of these two cases might differ (religious radicalism as opposed to secular nationalism), but the mechanism underlying both historical processes - the structural component, as it were - is essentially the same. The purpose of the movements in both cases is to rally the people around the flag by violently proposing a new social or political order by means of sabotaging and impugning the old system, and to evoke the magnificence of a bygone golden age as an emotive harbinger of a desired near future.

Conflicts of nearly infinite variety in the course of human history have at some stage in their development followed this template. But, to give an example of an increasingly probable new motive, not only for PVMs, but also for other actors in international politics, we may want to imagine that we are in the opening stages of an unfolding future drama, at the heart of which will be the long-term risks of absolute resource depletion. In its entire history, the human race has never had to face planetary overpopulation or resource scarcity equally affecting all parts of the globe as an existential threat.

That the goals of the "New Terrorists" are not as diffuse as they are made out to be can even be seen in instances of extreme motives. For example, in the case of apocalyptic cults with a predilection for terrorist tactics, it is possible to identify not only the motive but also the objective. If the stated motive 
and/or the objective of a PVM happen to be to end the world as we know it, the trick is not to get sidetracked by debating the sanity of such a position and plan, but to take it seriously and make it part of the strategic deliberations on counter-terrorist measures. This understanding is vital if the means by which such a group attempts to bring about the end of days involve weapons of mass destruction. Today, the destruction of the world, or large parts of it, by non-state actors, for whatever reason, is no longer the exclusive preserve of science fiction; it has become an international political and security risk that will stop at no border.

Millenarian fanatics, eschatological sects, and other kinds of apocalyptical movements have been around for a long time. Their frame of reference is very different indeed from the mainstream perception of reality. But to believe that this makes them any less rational and calculating in pursuit of their goals, or any less determined to realize their objectives, is a grave mistake. The history of the past thirty-odd years bears this out and requires no further explanation. While they certainly do not abound, there have been precedents for such events, including attempted, but largely foiled or otherwise unsuccessful, mass casualty attacks by apocalyptic (and in the United States also by right-wing) groups. Second, the proposition that the "New Terrorist" groups are organized along innovative lines cannot be upheld in the face of a past record that flatly contradicts it. Even the role model of the "New Terrorist" organizations, the operationally decentralized cell structure with its independent commands that has been successfully applied in the shape of Active Service Units (or ASUs, the smallest quasi-independently operating combat unit of the Provisional Irish Republican Army) fighting against the British armed forces and intelligence services in the past three decades, is still predicated upon the principle of a traditional hierarchical military chain of command.

Louis Beam's idea of "leaderless resistance" as an organizing principle of PVMs might indeed apply to exceptions to the rule - as has been apprehended by the U.S. Federal Bureau of Investigation (FBI) in relation to right-wing and extreme Christian fundamentalist groups in the United States - but it certainly does not apply to an alliance system of PVMs based on a culturally ingrained pecking order originating in a quintessentially hierarchic Islamic creed, such as Al-Qaeda. As David Tucker has shown, the "striking thing about the networked structure of the new terrorism is that it differs little from the structure of the old terrorism," and goes on to cite the well-known example of the PLO (Palestine Liberation Organization), the exemplar of a terrorist umbrella organization, if there ever was one, drawing together a multiplicity of Palestinian secular political movements and their respective military wings. More generally, terrorist alliance systems in the shape of stable and ephemeral marriages of convenience, instrumental and ideological coalitions, umbrella organizations, and other forms of organizational superstructures are not at all new to PVMs.

One cluster of terrorist organizations that features complex, conflictive, hierarchical, and decentralized interrelationships, and which has been 
active in the greater Middle East since the early 1980s, may here serve as a contemporaneous example. I propose it here as an alternative to the lurid conception of the ostensibly new "global terrorist network." According to the intelligence sources that are largely in line with a historically recurring terroristalliance thesis, it is the Islamic Republic of Iran (specifically its secret services MOIS/VEVAK, the successor to the Shah's dreaded SAVAK, and the elite Jerusalem Force of the Iranian Revolutionary Guards, the Pasdaran), above all other actors, that is expanding its managerial and leadership role in the coordination of PVMs in the greater Middle East.

Through the good offices of Imad Fayez Mugniyah, Hezbollah's director of foreign operations, the Iran connection links Al-Qaeda to the Shi'ite militia organization Hezbollah, and - in a deadly coalition - to the predominantly Sunni Palestinian groups Harakat al-Muqwawanah al-Islamiyya (HAMAS), Jihad al Islami, and the Sunni radical group Usbat al Ansar ("Federation of Partisans") operating in southern Lebanon. The alliance of PVMs supported by Iran also gained notoriety as an accessory to the intercepted smuggling of military contraband on behalf of Yassir Arafat's Palestinian Authority (or PA, the official governing body of autonomous Palestinian territories in Gaza and the West Bank after 1993) aboard the freighter Karine- $A$ in the Red Sea in January, 2002.

An alliance of sub-state actors employing terrorist tactics, supported by a state sponsor and operating out of a defined region, is not nearly as dramatic as the constantly promoted image of a global conspiratorial network, such as Al-Qaeda. But at least it exists. Conversely, even if Al-Qaeda encompasses the occidental and oriental civilizations in terms of its documented operational reach, this at best makes it a "trans-regional terrorist network" in Southeast and Central Asia, the Mediterranean (including North Africa), the greater Middle East, Western Europe, and the U.S. That is still a far cry from being an organization that is active on a truly global scale, which, in turn, indicates that the network of its deployable operatives does not (yet) span the globe.

Third, if there are indeed substantive differences between the older kind of terrorism and the "New Terrorism," they are, if anything, not qualitative, but quantitative - with exclusive reference to the dimensions of an attack and its consequences. The ability to inflict greater casualties by deploying weapons of mass destruction can be understood as constituting a quality unto itself, but, again, the point is that this is not a new phenomenon in the history of armed conflict; only the potential destructive scale of modern WMD in the hands of PVMs itself is truly unprecedented. For example, the conscious deployment of biological weapons, resulting in mass casualties, has precedents in the later Middle Ages, the Renaissance, and the Early Modern period in Europe and the Americas.

Admittedly, in the centuries prior to the twentieth century, the efficiency of non-conventional warfare and weapons, such as the premeditated spread 
of endemic pathogens, was, to cite only one example, nowhere close to the ghastly death toll exacted by mustard gas over the course of the First World War. But, in essence, crudely weaponized pathogens did exist in the past, and they were deployed by a variety of actors. The "political terrorists" of the 1970s and 1980 s in the West were also sensitized toward the potential uses of non-conventional weapons; those having shown an interest in chemical and biological weapons include a staggering variety of PVMs, from the Weather Underground and the Rote Armee Fraktion (Red Army Faction, or RAF) to the Covenant, Sword, and Arm of the Lord (or CSA, a paramilitary survivalist group active in the U.S.).

Therefore, the threat of "loose nukes," and the threat posed by other poorly protected non-weaponized but weapons-grade nuclear materials, has been exacerbated but not initiated by the collapse of the Soviet Union. Equally, more recent apprehensions about the deployment of radiological bombs can be traced to the growing awareness of states - and, hence, sub-state actors - of the crude weapons-potential inherent in low-enriched uranium and spent fuel, and to the knowledge of how inadequately such materials are currently protected against theft.

What does set the PVMs of the twenty-first century apart from their predecessors, I will argue, is not the threatened, or even the effective, use of radiological, biological, or chemical warfare agents. Instead, it is the scale and, more critically, the scalability, of conventional and unconventional mass destruction and disruption by PVMs, and how this threatened or actual use of it translates into psychological leverage. Put differently (and rather more pertinent to our present times), the combination of the technology to inflict mass casualties measured in the hundreds of thousands, or even in the millions, on the one hand, and the increasing likelihood of the acquisition of the means to bring about such massive destruction of life by sub-state actors on the other constitutes the only evidently innovative aspect in the development of contemporary terrorism.

This last point is especially relevant when juxtaposed with the oftenrepeated assertion that the objectives of the "New Terrorists" are less clearly delineated than those pursued by their predecessors. In direct contradiction to such a view, the desire and the will to hasten the coming of Armageddon exhibited by some millenarian cults (e.g. Aum Shinriko) in the age of WMD proliferation has over the course of the 1990s been transformed into a very concrete course of action in pursuit of a final objective; it therefore represents an immediate threat. Ultimately, the means and ends of even the most radical PVMs are as clear today as was the case some twenty years ago. But today's PVMs are even more dangerous than their antecedents, precisely because they have not changed their values - i.e., their outlook, their motives, and their interpretation of their religious, political, and social environments - in relevant ways.

If we accept the proposed criticism made so far vis-à-vis the concep- 
tion of the "New Terrorism," it may at first glance appear as if only the perpetrators" "tools of the trade" have undergone change - their arsenal having grown from automatic rifles, explosives, and grenades to weapons of mass destruction and conventional heavy military-grade equipment - while the terrorists themselves have remained the same. ${ }^{6}$ Admittedly, in some instances, terrorist target selection has become bolder in the last few years, as was evidenced by the incidents of September 11, 2001. In other cases, their objectives have become more ambitious, such as the acceleration of Armageddon. These tendencies can both be at least partially explained by the circumstance that the potential to inflict a higher quantity of casualties also gives groups more leverage to realize their respective demands, or to achieve their objectives in the face of, and despite, overwhelming incumbent military superiority, as exemplified by the United States' conventional military forces.

Hence, it is a potentially costly misconception to assume that PVMs themselves are fundamentally different, that they have substantially revised their psychological make-up and reshaped their motivational landscape, or even to question the fact that they do remain organized in groups (albeit more or less immediately subject to central control), all because of the accessibility of weapons of mass destruction following the end of the Cold War and the recrudescence of religious fervor after 1979. This analysis holds true, if only because the PVMs of our own day and age remain subject to the constraints imposed by the bounds of their own rationality, whatever they may be. That a rational system of thought - including highly idiosyncratic, radical variants thereof - is also subject to change over time is not disputed here, nor is it denied that PVM decision-making processes and factors did very likely undergo some change under the influence of more readily available weapons of mass destruction.

Conversely, PVMs are indubitably products of their own environment. It follows that they are not alien to the reality we share with them, and that their reasoning is therefore also not beyond comprehension. The PVM perception of reality represents a valuable inferential basis for actor-centered analysis. While calling terrorists and their organizations "new" or irrational will not make them go away or attenuate the threat they represent, the challenge rests in secondguessing them on their own intellectual turf. This is a feasible course of action, but only if we commit resources to qualitative research with a view to achieving some measure of understanding of what makes them tick - of investigating what Martha Crenshaw referred to as an "autonomous logic that is comprehensible, however unconventional." And if PVMs' motives, objectives, and modi

\footnotetext{
${ }^{6}$ The exclusion of scalable weapons of mass disruption, such as electronic attacks on computer networks, various types of information operations, and high-energy pulse, blast, or focal weapons, is intentional.

${ }^{7}$ Martha Crenshaw, "The Psychology of Terrorism: An Agenda for the $21^{\text {st }}$ Century," 410; JeanFrancois Meyer, “Cults, Violence and Religious Terrorism: An International Perspective,” Studies in Conflict and Terrorism 24 (2001): 372.
} 
operandi can be fathomed, then they can be defeated.

In the light of the centuries-old historical record covering both insurgent and incumbent use of terrorist tactics, the distinction between the older terrorism and the "New Terrorism" is artificial at best, and the conception itself is rendered tautological and quite probably otiose. On the one hand, this is because the differentiation it seeks to create is a matter of perspective, and in some cases, as has been pointed out previously, may serve as a definitional "Trojan Horse" to an instrumental set of values advocated by insurgents or incumbents. It is therefore potentially interest-driven, and hence not beyond suspicion. On the other hand, if we scrutinize some of the key arguments quoted in support of the "New Terrorist" thesis - i.e. the absence of clearly identifiable groups among new actors on the international stage, unclear or new motives, diffuse objectives, and a high frequency of greater lethality in recent attacks - then the attempted differentiation from earlier variants of terrorism is also not convincing on the basis of the evidence.

Aside from its evocative force, the "New Terrorism" concept does not offer any added value to the way we think about terrorism. Moreover, the circumstances that gave rise to the concept are problematic. The issue of vested interests as a driving force behind the formulation of the "New Terrorism" paradigm has also been addressed by the late Ehud Sprinzak, who bluntly contended that "the threat of superterrorism is likely to make a few defense contractors very rich and a larger number of specialists moderately rich as well as famous." To Sprinzak, "the debate [on the "New Terrorism"] boils down to money."

\section{The Double-Edged Nature of Impact Scalability and the Dynamic of Reciprocal Threat Perception}

As shown in the preceding pages while reflecting upon the motives, objectives, organizations, and means of PVMs in the past, nothing really is intrinsically new about the "New Terrorism" paradigm - excepting the consensus among experts in the field of terrorism research that weapons of mass destruction in our day and age are more likely to be deployed by sub-state actors than in the past. Even so, the question of whether such a perspective is a mass media-driven figment of public imagination that suits certain vested political interests that have their own budgetary agendas would almost certainly further dilute the above outlined paradigmatic project and the expert consensus on the PVM-WMD threat to a merely conjectural supposition. Again, the expert assessment prevails, because weapons of mass destruction certainly appear to have become increasingly accessible in the post-Cold War period. On this issue, Morten Bremer Maerli asserts that "the overwhelming majority of incidents ... do not reflect any significant escalation of the mass destruction threat, but rather a

${ }^{8}$ Ehud Sprinzak, “The Great Superterrorism Scare,” Foreign Policy (Fall 1998): 6, 7; version cited at www.findarticles.com/cf 0/m1181/1998 Fall/56021078/print.jhtml 
growing interest in non-conventional weaponry among politically and religiously motivated groups and individuals."

This is not to say that there is no substance to the fears expressed by theorists of the "New Terrorism." Even if the interest of such groups has not yet been successfully acted upon with respect to modern WMD, the threat remains. This is true in spite of massive counter-proliferation endeavors, such as the Nunn-Lugar Act, passed in the United States Congress in 1991, and due to the fact that PVMs might consider the use of nuclear, chemical, or biological weapons an acceptable, or even an attractive and "prestigious" means to an end, especially in the shape of a credible threat or deterrent vis-à-vis a more potent opponent. Indeed, in the wake of the Cold War, apprehensions concerning PVM acquisition of modern WMD are not without substance. While the most recent Gulf War was fought with the objective of stripping Iraq of its alleged WMD capabilities, apprehensions are rising amid controversial reports of the successful acquisition of weaponized chemical warfare agents produced in Iraq by AlQaeda via Usbat-al Ansar, an affiliated Lebanese Sunni PVM.

This threat appraisal deriving from the "New Terrorism" paradigm is probably somewhat accurate, albeit with a single exception and corollary to the argument concerning weapons of mass casualty developed in this essay, and in the context of the wider debate on terrorism: PVMs' awareness of a newfound, potentially unfettered capability to size the scale of the impact of their attacks. To date, the currently feasible trinity of the convergent will, ability, and capability of PVMs to inflict mass casualties, bring about the destruction of entire urban areas, and occasion immeasurable trauma in the public psyche on a scale hitherto only conceivable in an armed conflict beyond the threshold of interstate war, has no parallel. Indeed, this condition constitutes a significant historical singularity. In the near future (for which the present is somewhat indicative), PVMs' capability of almost limitless "impact scalability" will be, and is already taking shape as, the single most important contributing factor to a radical transformation of terrorism, and indeed of warfare in general. It will give new meaning to the notion of "strategic asymmetry."

In order to better envision this idea, imagine a band of radical militants successfully forcing the most powerful nation on the planet to its knees by threatening to deploy a substantial nuclear, chemical, or biological in the wake of a number of successful minor attacks with WMD that cause mass casualties. If anything, it is this "impact scalability" at the beck and call of terrorist actors that would, and to some extent already does, make PVMs more dangerous now than ever before. Impact scalability expands the spectrum of terrorist tactics' asymmetric property in that it allows PVMs to calibrate even attacks carried out using WMD according to their requirements.

\footnotetext{
${ }^{9}$ Morten Bremer Maerli, "Relearning the ABCs: Terrorists and "Weapons of Mass Destruction,", Nonproliferation Review (Summer 2000): 110 (italics mine). On this issue in regard to chemical and biological weapons, see note 17 below.
} 
But while the issues concerning the means - finances, logistics, weapons, etc. - have been discussed at large in the debates on the "New Terrorism" and nonproliferation, the multiple non-material factors, such as the specifics of background, environment, and other idiosyncrasies that inform the motives and the perceived reality, as well as the resulting political and strategic priorities, of PVMs currently summoning up the will to deploy weapons of mass destruction, have not yet been exhaustively investigated. And although some have ventured into this terra incognita of the violent PVM mindset, a not insignificant development responsible for the shaping of the terrorism risk perception has been largely neglected: the dynamic of reciprocal threat perception between perpetrators and victims of PVM mass casualty attacks.

The nature of the relationship between the waxing willingness of PVMs to use conventional or non-conventional mass casualty weapons and the fearful expectation of ever more destructive mass casualty attacks involving WMD, engendered by the mass media-induced "superterrorism scare" (to borrow Ehud Sprinzak's wording) in the broader public, is what makes today's PVMs more dangerous than before. The reason for this, I would argue, is banal. In an age in which the specter of "superterrorism" reigns supreme and has successfully undermined governmental and public confidence in the past decade, most PVMs very likely are under increasing pressure to reinforce the popular nightmare of mass casualty terrorism that is the obsession of Western governments, their allies, and the mass media alike.

This absurd situation prevails precisely because, in a bizarre way, the power to immobilize a powerful state by threatening to use mass casualty weapons is not only a critical asset to PVMs, but has also been at the center of public expectation for at least a decade, and is considered even more probable today. And the reservoir of public expectation/apprehension continues to grow. This condition insidiously correlates with the rising pressure on PVMs to deploy mass casualty weapons in order "comply" with public apprehensions and thus to maintain their own credibility vis-à-vis their audience. Conversely, PVMs are also subject to pressures building due to the opportunity presented to them by, and resulting from the impact of, the dynamic of reciprocal threat perception.

In summary, because PVMs themselves have not fundamentally changed in terms of their motives and objectives, the question of whether terrorism is more dangerous today or not has very little to do with the body of analyses that gave birth to the conception and recent rendition of the so-called New Terrorism. Instead, this critical query is intricately linked with the interdependent problems of the long-term failure of nonproliferation; the consequent increased probability that weapons of mass destruction will sooner or later come within reach of terrorist actors; the concomitant new development of PVMs adjusting their strategy and objectives to include the augmented "impact scalability" of unconventional means at their disposal; and the perceived threat 
that they represent, as well as the general sense of insecurity this situation fosters. Most importantly, the danger of mass casualty terrorism in the present has become more tangible and acute because of the resulting "reciprocal dynamic of threat perception." In contrast to the mere hypothetical threat, as it is perceived by expert participants integral to this process, I propose that it is the "reciprocal dynamic of threat perception" which acts as the principal structural catalyst in the triggering of mass casualty terrorist attacks with conventional or unconventional weapons.

Considering the discussion so far, it would probably be more productive and sensible to refer to a recrudescence, or reanimation, of earlier types of terrorism-users (e.g., the Zealot Sicarii referred to earlier in this essay, or the Islamic sect of Assassins, who centuries ago instrumentalized premeditated, systematic murder as a means of terrorizing their enemies and of cowing their opponents into submission, even at the cost of their own lives, not unlike their modern Middle Eastern counterparts) than to portentously proclaim the advent of the "New Terrorism." The bottom line is that certain simply do not change all that much. Perpetrators still intend to generate fear by using terrorist tactics. Whether the goal is the aggravation of fear among the few or among the many is a completely different issue, one that effectively has always been constrained by the means at the actors' disposal. Only to a lesser degree has the use of terrorism been dependent upon grand strategy and optimistic operational planning. The reason for this is that PVM arsenals have hitherto proved no match for those at the disposal of their opponents.

With the advent and recent exacerbation of WMD proliferation, terrorism's fortunes may have undergone an advantageous reversal; the very circumstance of unconventional weapons accessibility could be responsible for such a development, but certainly not to the exclusion of other reasons. Now that maximum firepower in the broadest sense is no longer out of reach, motive, as opposed to hardware, may in the future assume the determining position in the framing of PVM strategy, and in the decision-making process concerning the deployment of mass casualty weapons.

In other words, it is not exclusively the fact that these weapons have become available that makes contemporary PVMs more dangerous; it is the realization by these movements in the past decade of what they can achieve by credibly threatening their deployment in pursuit of even the most audacious, but highly specific, objectives, such as the destruction of a state's capital, or the end of the world. More critical still is the fact that in order to achieve "WMD credentials," PVMs will almost certainly have to deploy these fearsome weapons as proof of their willingness to use them. Unpredictable "ego-trips," impulsive revenge, competitive "showing-off" - a whole range of unfathomable, diacritic, and spontaneous internal group dynamics and other inter- and intra-PVM motives also enter into this scenario as probable factors in the non-premeditated category. 
The glaring asymmetry of impact scalability in the service of PVMs comes to the fore in scenarios in which the effective use of WMD is not even necessary. Because of the widespread fear of the recently perceived mass casualty terrorist threat, PVMs might not have to do their worst in order to achieve their end, always provided that the objective is not the destruction of life on this planet. Bruce Hoffman believes that

...even the limited terrorist attack involving a chemical, biological, or radiological weapon on a deliberately small scale could therefore have disproportionately enormous consequences, generating unprecedented fear and alarm and thus serve the terrorists' purpose just as well as a larger weapon or more ambitious attack with massive casualties could. ${ }^{10}$

Although Hoffman's observation is highly significant in itself, it does raise some issues. To begin with, such an operational implementation of sophisticated high-tech WMD presupposes considerable expertise on the part of the deploying party, as well as the availability of advanced weapons technology in the field of delivery systems, which is indispensable to controlling the dimensions of an attack. Second, and more pertinent to the present purpose, Hoffman's observation raises the point of reciprocity in the idea of the reciprocal dynamic of threat perception. Not only does the fear of mass casualty terrorism pressure terrorists into complying with the public "standard" or "benchmark" of fear, it also maximizes the effects of the threatened or actual use of a comparatively small radiological, biological, or chemical weapon.

This dangerous dynamic therefore constitutes a development that is beyond anybody's control and threatens to continue of its own volition. Its driving forces - impelling public fears of WMD terrorism and terrorists' appraisal of the largely untouched and highly attractive leverage against governments represented by the mere threat of such weapons' destructive use - are very difficult, if not impossible, to interrupt.

A first step toward countering some of the worst effects of the dynamic of reciprocal threat perception beyond government organizations could be taken by the proactive sensitization of the mass media, and especially the broadcast media, to the destabilizing potential of the dynamic of reciprocal threat perceptions, and the curbing of economic incentives and pressures in the mass media, as well as the reduction of their adverse impact on the manner and quality of reporting among journalists. More controversially, the institution of selfcensorship and the imposition of stringent restrictions on irresponsible, sensationalist reporting by leading members of the various media branches in the interest of public safety ought to be evaluated anew.

Impact scalability and the pressures on the perpetrators and victims of

\footnotetext{
${ }^{10}$ Bruce Hoffman, "New Forms of Terrorism and The Threat of Terrorist Use of Chemical, Biological, Nuclear and Radiological Weapons," in Terrorismus als Weltweites Phänomen, eds. Kai Hirschmann and Peter Gerhard (Berlin: Berliner Wissenschaftsverlag, 2000), 43.
} 
terrorism that arise from the self-sustaining dynamic of reciprocal threat perceptions ought to be high-priority issues in the field of contemporary terrorism research. In the light of purported advanced weapons research involving the development of sophisticated and controllable delivery systems for chemical and biological weapons, such as dirigibles and spatially limitable aerosols, and incrementally deployable viruses (infector and trigger viruses), work on the effects of impact scalability of terrorist attacks becomes even more pressing. Atomic weapons research, for example, has culminated in the development of precision low-yield nuclear weapons. Moreover, the proliferation problems resulting from the dissolution of the Soviet Union may here serve as an example of how advanced weapons technology, in the form of its products - the weapons - and its creators - the scientists - have in the meantime become not only accessible but available to sub-state actors. Once out of the control of the government responsible for their development, either by design or by mistake, advanced precision delivery systems would draw to WMD as vehicles to threaten mass casualty terrorism even those PVMs that have hitherto shied away from considering them as an option because of their dependency upon "constituencies." To continue this train of thought, these new users of biological and chemical weapons would likely be those with the most operational experience in applying conventional terrorist tactics and asymmetric warfare: the long-enduring, undefeated nationalist-irredentist and ethnic-separatist groups, such as the IRA or ETA.

Yet still worse is the idea that controllable delivery systems for biological and chemical weapons in the hands of PVMs would lower the threshold to use weapons of mass destruction in fulfillment of the "proof of concept" criteria that a terrorist group is in possession of an operational unconventional mass casualty weapon; the damage would not be as indiscriminate as with "ordinarily" deployed biological or chemical weapons. If a group actually possessed such a precision delivery system, it follows that the deterrent value represented by the risk of endangering one's own constituents would be considerably diminished.

In evident contrast to established usage in the tradition of top-down policy analysis, the twin concepts of impact scalability and the dynamic of reciprocal threat perception, previously identified as a likely catalyst for the future PVM use of unconventional mass casualty terrorism, strive to approximate the bottom-up nature of asymmetric warfare and are thus intricately linked to the terrorist actors as the terminus a quo of terrorism. Once the means become available to the WMD perpetrator, knowledge of his psychological individual or group profile - of the way his mind works - will become the most powerful asset in the service of those forces opposing him.

This actor-centered approach also differs from a widespread emphasis on the consequences of terrorist acts and the interpretation thereof by the mass media, or representations of PVM attacks generated in the broader context of the public discourse on the terrorist threat; it has little patience with the evanes- 
cent, faceless threat encountered on the policy level. After all, just how much of Al-Qaeda has really been authored by Osama Bin Laden, Muhammed Atef, and Ayman al Zawahiri (all members of Al-Qaeda's guiding shura council)? And to what extent is the public perception of this organization driven by the absence of a serious antagonist to the West following the cession of Cold War tensions, Western governments' sudden awareness of new vulnerabilities, and incentivedriven reporting by the broadcast media?

\section{Understanding Impact Scalability, the Dynamic of Reciprocal Threat Perception, and their Strategic Implications: The Case for an Actor- Centered Approach to Terrorism Research}

I want to close this essay with a few thoughts on the manner in which we conduct research on, and how it affects our perception of, PVMs and terrorism. In an era of possible, even probable, deployment of weapons of mass destruction, the impact of which is in some manner controllable and at the disposal of substate actors with known terrorist track records, a stringent appraisal of the PVMs that are potential perpetrators of conventional and, especially, unconventional mass casualty attacks, is vital.

The urgency of the problem in the near future may increase dramatically, because of the impending revolution in military affairs with respect to dirigible and spatially limitable delivery systems for non-atomic weapons of mass destruction. If we consider strategic scenarios for contemporary states' foreign and security policy, one possibility that never leaves the detachedly paranoid imagination of the defense analyst is that of the sub-state actor armed with WMD provoking an international crisis by taking the offensive against a state with a scaled, surgical attack with unconventional WMD possibly on behalf, and with the clandestine support, of another state. The likely consequence of such an event is a minor to major destabilization or even disruption of the global strategic security environment.

The potential capability of PVMs to calibrate the impact of a radiological, biological, or chemical attack exacerbates this situation. It would mean that perpetrators of future terrorist acts could scale an attack to their utmost advantage in a precisely calculated way in order to provoke desired responses from states, to cow governments, and to surgically stimulate, aggravate, and exploit panic among the population. ${ }^{11}$ The impact scalability of unconventional weapons further refined by the revolution in the field of delivery systems, once their proliferation had begun, would put a powerful "surgical" weapon within reach of PVMs around the globe that is readily translatable into considerable

\footnotetext{
${ }^{11}$ I have excepted radiological dispersion devices from the list because they are weapons of mass disruption rather than weapons of mass destruction and cannot be surgically applied by definition. This is not to suggest that they could not be instrumentalized at all in such a scenario; their value to the perpetrators could be that of a positively scaled impact. Cf. Michael A. Levi and Henry C. Kelly, “Weapons of Mass Disruption," Scientific American (November 2002): 59-63.
} 
political capital and military leverage, since the likely opprobrium attaching to PVMs as a result of indiscriminate destruction caused by the use of WMD systems of the Cold War era and the more recent radiological dispersion devices would in such a case no longer apply in the way of a self-deterrent. PVMs that could even in a limited way influence the dynamic of reciprocal threat perception to their benefit - both public fears and the disposition of their members to deploy WMD - through the credible employment of impact scalability, would be in a position to dictate their terms to any government in the world.

The threat posed by PVMs willing to use WMD is probably even greater now and is, of course, not exclusively subject to influence by improvements in technology and delivery systems. For today, the disciplining force of the bipolar system, the oppressive awareness and brooding reality of nuclear holocaust lurking around the corner, the "red telephone" fail-safe mechanisms established following the Cuban missile crisis during the Cold War, are no more. Due to the weight currently attached to the threat scenario in private, public, and government circles of sub-state actors seeking to acquire WMD, the actual threat itself may well become a self-fulfilling prophecy according to the dictates of the dynamic of reciprocal threat perception. The more we achieve or manufacture consensus on being afraid of PVMs possibly deploying WMD - discriminately or indiscriminately - and the more we discuss and disseminate knowledge about this issue in the public domain and the corridors of power, the more we become accessories in the creation of the multilaterally perceived "merit" of the psychological potential of a weapon that can panic entire populations and hold to ransom governments; the more attractive we make the WMD option for terrorists; and the more likely the prospect of an PVM attack involving WMD becomes.

Therefore, an analysis of which PVMs are noted for a predisposition toward the use of unconventional weapons, and which are less inclined to use them, is a prerequisite for the establishment of priorities in the combating of terrorism and must serve as a road map for future policy-making in the area of national and multilateral counter-terrorism programs. Evidently, if we wish to pinpoint potential perpetrators of terrorist attacks involving WMD, there is no way around actor-centered analysis. This is especially relevant if we accept that the kind of intelligence and threat analysis that helps establish the identity of potential WMD terrorist perpetrators in the present is also critical to the overall effort of thwarting unconventional mass casualty attacks in the future. ${ }^{12}$

\footnotetext{
${ }_{12}$ Jean Pascal Zanders, "Assessing the Risk of Chemical and Biological Weapons Proliferation to Terrorists," Nonproliferation Review (Fall 1999): 26, 30. Although clearly lacking actor-centered analysis as a focus in his investigation, Zanders does review the "social environment and norms" of a PVM, but focuses on the "assimilation model for studying the demand side of the proliferation process in states." States and sub-state actors usually have different priorities, and models generally disregard exceptions to the rule. Both implicit assumptions - that state and substate actors are comparable in relation to PVM use of WMD, and that PVM behavior per se can be modeled - ignore the established diacritic nature of PVMs at the peril of voiding their very premises. PVMs tend to be unpredictable and hence exceptions to most rules.
} 
Conversely, generalizing the terrorist threat by abstracting it or quantifying data on PVMs invites the likelihood of an exponential trajectory of analytical error. The nomenclature of the generalization of terrorism in the form of sweeping, impersonal categories is symptomatic of its reductionist mindset (e.g., "the global terrorist network," "Middle Eastern terrorism," terrorism as a national-level risk, as opposed to a documented threat etc.). This reductionism, in turn, constitutes an invitation to deterministic thought; and determinism, by virtue of its model-like, teleological nature, is frequently quite removed from the nuts and bolts of reality.

Too often we are removed from the field of violence. We need to interact with those who are violent. The best research on small-group political violence is undertaken by researchers who, on some level, interact with the people being researched. Sampling is important. With every research method there is the possibility that respondents will tailor what they say to the expectations of the interviewer, for any number of reasons. Immersion in the research field and regular interaction with activists often allows one to overcome problems that plague the journalist, as well as the one-shot survey approach. ${ }^{13}$

It is evident that the consequences deriving from an analytical mistake caused by the exclusion of the evident idiosyncratic psychological backdrop of PVM use of terrorist tactics and the diacritic property of PVM decision-making, including the situational specificity of implementing impact scalability, could be catastrophic well beyond the benchmark of destruction established on September 11. And it is important to be clear about one thing: all attacks carried out on September 11 bear the imprint of the traditional, and not the "New," terrorism. In terms of the psychological impact and the economic disruption, but not necessarily the volume of casualties caused, September 11 will almost certainly be overshadowed by a PVM attack with unconventional weapons of mass destruction. The next attack is virtually guaranteed. ${ }^{14}$

On a fundamental level, the ability to learn how to think the way that terrorists do is the key to any sensible analysis of the terrorist threat. There are no objective indicators in aid of an assessment of the terrorist threat. Ex post facto examples too numerous to be listed here illustrate the preeminence of nonlinear and non-quantifiable determinants in the decision-making processes of PVMs. Likewise, the accuracy of prognostication is dependent upon the specificity, and not any presumed objective character, of intelligence and its contextualist interpretation, which in turn rests upon a solid understanding of the subjective reality of the actors.

${ }^{13}$ Robert W. White, "Issues in the Study of Political Violence: Understanding the Motives of Participants in Small Group Political Violence," Terrorism and Political Violence 12:1 (Spring 2000): 100-101.

${ }^{14}$ I understand that this assessment cannot escape being integral to the process of the dynamic of reciprocal threat perception as well too, but feels that tabling the issues addressed in this work outweighs other considerations. 
The rationale behind the use of terrorism is conditioned by a multiplicity of influences, some of which are likely not to be factored in by analysts due to insufficient information or understanding. Where the determinism germane to game theory and rational choice models will almost certainly fail to adequately capture the nature of a specific PVM phenomenon, the situational experience of role-playing and other scenario techniques still has a chance to produce insight, capture unpredictable behavior, and open up new perspectives.

An understanding of the PVM mindset is the best source for inferential analysis, which is especially important and practicable, for example, in the devising of guidelines for protective measures and countermeasures. This approach promises to produce the best clues about PVM decision-making processes and the mechanisms at work in the formation of objectives. C. J. M. Drake points to the significance of understanding this key lesson of PVM analysis:

A group's ideology is extremely important in determining target selection. It defines how the groups' members see the world around them. Events and the actions of various people - both potential targets and other actors - are interpreted in terms of the terrorists' cause... When a group takes the decision to use violence, an early step is to determine who or what will be attacked. The ideology of a terrorist group identifies the 'enemies' of the group by providing a measure against which to assess the 'goodness' or 'badness', 'innocence' or 'guilt' of people and institutions. ${ }^{15}$

One lesson of the attacks of September 11 is the need to move away from making assumptions about PVMs according to the dictates of the policy of the day, or on the basis of statistical evidence (that is of questionable value) on an issue that is intrinsically non-quantifiable. Countermeasures ought to follow understanding established by qualitative, as opposed to quantitative, research, and thus emphasize detailed actor-centered analysis. Terrorism is a "people business," period. In its most pronounced form, the argument raised here is to the academic sector what the increasingly urgent call for the augmentation of human intelligence (HUMINT) capabilities is to the world of secret services.

Frequently, government organizations remain unreformed, despite the self-evident fact that a more successful counter-terrorism policy is to a large extent predicated upon realizing the critical need to master the analytical challenges as determined by an hitherto underrated qualitative research. Reform also hinges upon a sensitization to the inherently questionable value of abstracted risk analyses, and an appreciation of the dangerous margins of error created due to their approximate nature in their role as determinants in the policy-formation processes.

${ }^{15}$ C. J. M Drake, Terrorists' Target Selection (Basingstoke: Macmillan, 1998), 23. 
We should first know who (actors, motives, and objectives) and what (organizations and capabilities) we are dealing with before jumping to conclusions, comparing and referencing fragments of information with a known, but possibly inapplicable, body of knowledge and committing resources to protect and counteract on that basis. Here introduced by way of a consultative theme, albeit sotto voce, is the warning not to make any assumptions about PVMs based on abstractions of terrorism. This is especially important, since such assumptions may enter governmental decision-making processes conducted by people with no, or only little, experience with terrorism, which in turn may translate into policy directives, gargantuan fiscal commitments, and superfluous exertions - and likely in the wrong places at the wrong time.

A case illustrative of government spending on the basis of originally quite pragmatic renditions of a perceived endemic terrorist threat that somewhere along the line became quite generalized and abstracted is that of the United States' sudden concern with its critical infrastructures. Massive government funds are being mobilized on behalf of Critical Infrastructure Protection (CIP) programs, which have been enacted on the legal basis of the Clinton Administration's Presidential Decision Directive Number 63 (PDD-63), signed in May 1998.

The U.S. federal government is presently confronted with the challenge of having to "minimize, with a limited amount of resources, the expected impact on the nation's critical infrastructure of any future terrorist attack."16 In spite of the wide scope of identified critical infrastructures to be protected, the U.S. government's inquiry has noted that "there will be a need to prioritize effort, to allocate limited resources in a way that can minimize the impact of any future terrorist attacks on the nation's infrastructure..."17 A report to Congress in August 2002 distinguished three criteria for determining allocation of federal funds in the spirit of PDD-63:

- Lack of redundancy, criticality of service provided, and robustness of a critical infrastructure;

- Cross-cutting vulnerabilities and potential solutions in infrastructures;

- Identification and determination of the quality of interdependencies between infrastructures.

About the last criteria, the authors of the report wrote: "Identifying and focusing on those assets that connect one infrastructure to another may be a costeffective way to reduce the overall impact of an attack."18 The irony of such a view is that, sensible though it may be with respect to cost-benefit arguments,

\footnotetext{
${ }^{16}$ John Moteff, Claudia Copeland, and John Fischer, "Critical Infrastructures: What Makes an Infrastructure Critical?" Report for Congress by the Congressional Research Service (Washington, D.C.: Library of Congress, 30 August 2002), 12.

${ }^{17}$ Ibid., 11-12.

${ }^{18}$ Ibid., p. 12.
} 
it implicitly assumes that PVMs will also recognize and identify the same interdependent infrastructures as priority targets. An error in this assessment would potentially offset any gain - financial and otherwise - in security to critical infrastructures. Significantly, the criteria established by the authors of the reports tasked with measuring the exposure and vulnerability of critical infrastructures exclude the one determining factor that could possibly allow them to assess the actual threat level and, hence, determine the degree and particular means of protection required: the terrorist actor.

A major problem with assessing vulnerabilities is that they seem to proliferate the closer one looks; threats, though dynamic and amorphous, are not as prone to spontaneously reproduce. While the definition of the former is an arbitrary exercise of questionable value whose only test is a terrorist attack, the analysis of latter constitutes a feasible enterprise with a considerable likelihood of situational gains and the possibility of supporting proactive intervention efforts (counter-terrorist operations).

Assessing exposure and vulnerability to terrorist attack without considering the origin of the threat - i.e. the actor - is hence at best a questionable pursuit, costly to the taxpayer. A couple of years prior to the publication of this Congressional report, an expert statement to the House of Representatives' Subcommittee on National Security, Veterans Affairs, and International Relations expounded in no uncertain terms:

Making decisions without commonly agreed upon threat and risk assessment carries the chance that important resource allocation decisions will be based on current beliefs and not on a well-grounded understanding of the problem at hand. The apparent over-reliance on worst-case scenarios shaped primarily by vulnerability assessment rather than an assessment that factors in the technical complexities, motivations of terrorists and their patterns of behavior seems to be precisely the sort of approach we should avoid. ${ }^{19}$

When reading John Parachini's critical statement, briefly reflect upon the point raised by Martha Crenshaw about how terrorism research may be event-driven and ponder Ehud Sprinzak's skeptical remarks about the "great superterrorism scare." ${ }^{20}$ Can we, therefore, allow "current beliefs" to exacerbate an "eventdriven" approach to terrorism research that, in turn, opens up the possibility of an exponential trajectory of analytical error? Can we afford to finance the protection of all identifiable critical infrastructures against all and sundry, more or less probable, threats emanating from PVMs? Finally, can we allow ourselves

\footnotetext{
${ }^{19}$ Statement of John V. Parachini, Senior Associate, Center for Nonproliferation Studies, Monterey Institute of International Studies, before the House Subcommittee on National Security, Veterans Affairs, and International Relations, in Combating Terrorism: Assessing the Threat (20 October 1999), 9 (italics mine). The full text of the statement is available at the website of the Federation of American Scientists: http://www.fas.org/irp/congress/1999 hr/991020-test2.htm.

${ }^{20}$ Crenshaw, "Psychology of Terrorism,” 21; Ehud Sprinzak, "Great Superterrorism Scare,” 33.
} 
to exclude the actor as the central piece of any threat analysis?

The unqualified answer to all these rhetorical questions is a resounding No. In the sense that it has less "ground" to cover than vulnerability and exposure analysis, actor-centered analysis is probably more efficient in the CIP context because it is geared toward the identification of the source of the threat. Common sense suggests that any CIP response must be calibrated in proportion to the effective PVM threat and relative to its target selection criteria. Defending critical infrastructures against all known factors contributing to its vulnerability renders the task of creating adequate protection virtually impossible, and thereby opens up previously nonexistent vulnerabilities. Seen this way, vulnerability analysis-based critical infrastructure protection may be instrumental in creating new vulnerabilities.

Also consider Parachini's remark on worst-case scenarios derived from vulnerability assessments as a benchmark for protective measures, and juxtapose it with the conception of impact scalability. PVMs might just succeed at destroying or impairing critical infrastructures because they decide not to play along with the CIP scenario "scriptwriter," who derived his or her assessment from a "vulnerability perspective," but instead "undercut" the expected intensity of an attack by selecting an atypical, hard target and attacking it with cutting-edge conventional means. Imagine that the critical infrastructure involved is a military installation, for example a silo housing mirved intercontinental ballistic missiles, or an unfathomable symbolic target with meaning to the actor that is not apparent to the defender.

On the general level, the overall objective of methodological advances in the study of terrorism will eventually have to be a consolidation of analytical methods and practices - a convergence of risk analysis and intelligence analysis. Actor-centered analysis, however, must become central to both, for if we desire to both understand the threat and extrapolate the risks emanating from PVMs, we are compelled to understand their idiosyncratic "logic," which is inarguably the inferential basis relative to their practices, objectives, and motives.

In pursuit of this task, we do not have to reinvent the wheel, and we may take recourse to the existing methodological wealth: from intelligence analysis practices, such as the Analysis of Competing Hypotheses, to micro-historical approaches, to case studies, to Behavioral Evidence Analysis in the field of criminal investigative psychology. Because any profile of a PVM hinges upon the perspective (i.e., threat perception) we adopt, we must be careful not to portray static images, but rather endeavor to create dynamic motion pictures sustained by a multi-disciplinary feed from monitoring activities in the field and insight gained in the study. Permitting ourselves to better understand the context within which, and out of which, PVMs operate constitutes our best hope of interdicting future attack and damaging PVMs' personnel base and their capabilities. Learning how the authors of terrorism think and make decisions is our best line of defense against the potentially more potent terrorism of the future. 


\section{Bibliography}

Crenshaw, Martha. "The Psychology of Terrorism: An Agenda for the 21st Century." Political Psychology (2000).

Creveld, Van. The Transformation of War. New York: Free Press, 1991.

Hoffman, Bruce. "New Forms of Terrorism and The Threat of Terrorist Use of Chemical, Biological, Nuclear and Radiological Weapons." In Terrorismus als Weltweites Phänomen. Berlin: Berliner Wissenschaftsverlag, 2000.

Hoffman, Bruce. Inside Terrorism . London: Victor Gollancz, 1998.

Kushner, Harvey. "The New Terrorism." In The Future of Terrorism: Violence in the New Millennium. Thousand Oaks, CA: Sage Publications, 1998.

Laqueur, Walter. The New Terrorism. Fanaticism and the Arms of Mass Destruction . London: Oxford University Press/Phoenix Press, 2001.

Lesser, Ian O.. "Changing Terrorism in a Changing World." In Countering the New Terrorism. Santa Monica: RAND Corporation, 1999.

Levi, Cf. Michael A., and Henry C. Kelly. "Weapons of Mass Disruption." Scientific American (2002).

Maerli, Morten Bremer. "Relearning the ABCs: Terrorists and "Weapons of Mass Destruction"." Nonproliferation Review 110 (2000).

Meyer, Jean- Francois. "Cults, Violence and Religious Terrorism: An International Perspective." Studies in Conflict and Terrorism (2001): 24.

Sprinzak, Ehud. "The Great Superterrorism Scare." Foreign Policy 6, no. 7 (1998).

Tucker, David. "What is New About the New Terrorism and How Dangerous is It?" Terrorism and Political Violence 13, no. 3 (1991).

White, Robert W.. "Issues in the Study of Political Violence: Understanding the Motives of Participants in Small Group Political Violence." Terrorism and Political Violence 12, no. 1 (2000): 100-101 .

Zanders, Jean Pascal. "Assessing the Risk of Chemical and Biological Weapons Proliferation to Terrorists." Nonproliferation Review (1999). 